\title{
Ser médico de (sua) família...
}

Being (your) family physician...

Ser médico de (su) familia...

José Agostinho Santos ${ }^{1 *}$

Palavras-chave:

Relação Profissional-Família

Relações Familiares

Adaptação Psicológica

Doente Terminal

Keywords:

Professional-Family Relations

Family Relations

Psychological Adaptation

Terminally III

Palabras clave:

Relaciones Profesional-Familia

Relaciones Familiares

Adaptación Psicologica

Enfermo Termina

\section{Resumo}

Poderá a relação médico-paciente somar-se a uma relação familiar, com benefício para a pessoa, em determinadas situações clínicas? Luís tem 59 anos e um filho, Abel, médico de família. Perante um quadro de perda de peso e adenomegalias, Abel percebe estar diante de um cenário clínico com elevado grau de suspeição. Relembra as mudanças comportamentais anteriores assumidas por Luís. Todas elas foram iniciadas após o aconselhamento médico pelo filho. Abel identifica o medo de Luís em iniciar qualquer investigação na sua saúde e reconhece a solidez e a confiança fornecidas pela afetividade entre pai e filho numa relação que começara de forma casual e imprevista. Ao contrário do que sempre pensara fazer, Abel assumiu-se como médico do seu próprio pai. 0 diagnóstico viria a revelar um adenocarcinoma gástrico. 0 impacto da transmissão das más noticias e do sofrimento na pessoa pôde ser atenuado por ter sido realizado pelo filho médico.

\section{Abstract}

Can the doctor-patient relationship add up to a family relationship, with benefit to the patient, in certain clinical situations? Luis is 59 years-old and has a son named Abel, who is a family doctor. Given the clinical scenario of weight loss and enlarged lymph nodes, Abel perceives a high degree of suspicion. He recalls the previous behavioral changes that Luis has undergone. All of them started following the medical advice by his son. Abel identifies the fear of Luis to start any research on his health and recognizes the strength and confidence provided by the affection between father and son in a doctor-patient relationship that began casually and unexpectedly. Rather than what he always thought he would do, Abel becomes the attending physician of his own father. The diagnosis reveals a gastric adenocarcinoma. The impact of communicating the bad news and the suffering of the patient could be alleviated if performed by his own son.

\section{Resumen}

Puede la relación médico-paciente sumarse a una relación familiar, trayendo beneficios para el paciente en determinadas situaciones clínicas? Luis tiene 59 años y un hijo, Abel, que es médico de familia. Delante de un cuadro de pérdida de peso y adenomegalias, Abel tiene la fuerte sospecha de tratarse de un escenario clínico. Recuerda los cambios de comportamiento anteriormente vivenciados por Luis. Todos ellos comenzaron después de los consejos médicos de su hijo. Abel identifica el miedo que Luis tiene de investigar su salud y reconoce la fuerza y la confianza proporcionada por una relación afectiva entre padre e hijo como base para una relación médicopaciente, que comenzó de manera casual e inesperada. Contrariamente a lo que siempre pensara, Abel se convierte en médico de su propio padre. El diagnóstico reveló luego un adenocarcinoma gástrico. El impacto de las malas noticias y el sufrimiento del paciente pudieron ser aliviados por el hijo médico.

\footnotetext{
${ }^{1}$ Unidade de Saúde Familiar Lagoa, Senhora da Hora, Portugal. zeagostinho@hotmail.com

*Autor correspondente

Fonte de financiamento: nenhuma.

Conflito de interesses: declara não haver.

Recebido em: 11/12/2011

Aprovado em: 15/10/2012
} 


\section{Introdução}

Boa parte dos médicos presta cuidados de saúde aos seus familiares. Um estudo americano revelou que 99\% dos médicos recebem pedidos de aconselhamento, diagnóstico ou tratamento de seus parentes ${ }^{1}$.

Diversos motivos conduzem ao estabelecimento desta singular relação médico-pessoa. O pedido expresso do parente constitui o motivo principal, realçando-se a proximidade familiar como atenuadora de custos e de inconveniências de deslocamento à unidade de saúde. A este fato somam-se o desconforto do médico em solicitar a observaçáo por um colega e a inibiçáo em recusar o uso do seu olhar clínico ${ }^{2-4}$.

Distintas sociedades médicas abordam esta temática. $\mathrm{O}$ American College of Physicians e a American Medical Association desaconselham os cuidados prestados aos familiares ${ }^{5,6}$. Ressalvam, porém, que cuidados fornecidos em situaçóes de emergência ou envolvendo problemas "menores" poderão ser aceitáveis ${ }^{6}$. O Novo Código de Ética Médica brasileiro não refere este aspecto em seus artigos ${ }^{7}$.

A literatura registra problemas que podem ser produto desta peculiar relação. A natureza informal do ambiente familiar poderá corroer a extensão da coleta de dados feita na anamnese, ao ser marcada pela ausência de registros clínicos e pela hesitação em questionar sobre hábitos nocivos ou

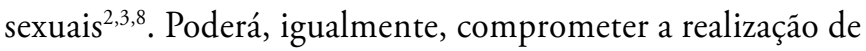
procedimentos invasivos no exame físico, em parte devido à ausência de instrumentos adequados no domićlío familiar ${ }^{2,8,9}$. Tal poderá traduzir-se num menor rigor do diagnóstico, tratamento ou seguimento. $\mathrm{O}$ comprometimento a estes níveis é também interpretado como consequência da interferência do excessivo envolvimento emocional na formulação do raciocínio médico ${ }^{2,3,4,8,9}$.

São diferentes os fatores que interferem na decisão de fornecer cuidados médicos ao seu familiar, tais como, a qualidade da relação afetiva familiar, a sua especialidade médica, o grau de severidade patológica ou o tratamento possível $^{10}$. Puma et al. criaram uma série de sete questóes que, apelando ao processo cognitivo do médico para elaboração das sete respostas, poderá ajudá-lo na adoçáo de um caminho (Quadro 1) ${ }^{11}$.

Independentemente da evidência científica para a decisão, o clínico enfrentará um dilema. Diversas interrogaçóes permanecem perante aquela pessoa única, que é também familiar. Uma delas não será, certamente, rara: não poderá a relação médico-paciente somar-se a uma relação familiar, com benefício para a pessoa, em determinadas situaçôes clínicas?
Quadro 1. Autoanálise da prática clínica de médicos potencialmente cuidadores de seus familiares (desenvolvida por Puma et al.. ${ }^{11}$.

\section{Sete questões para autoanálise (para médicos) ${ }^{\star}$}

1. Estarei habilitado para corresponder às necessidades dos meus familiares?

2. Serei demasiado próximo para inquirir os meus familiares sobre as áreas intimas na coleta de dados da história clínica, para fazer um exame físico completo e, caso necessário, transmitir más notícias?

3. Serei suficientemente objetivo para não prestar cuidados de saúde inadequados, em demasia ou deficitários?

4. Será que o meu envolvimento médico poderá provocar ou intensificar conflitos intrafamiliares?

5. Será que a compliance dos meus familiares será maior se os cuidados de saúde forem prestados por um médico sem grau de parentesco?

6. Será que permitirei que o médico a quem referenciarei os meus familiares exerça a sua prática clínica?

7. Serei capaz de ser responsável por esta prestação de cuidados perante os meus colegas e perante o público?

*Tradução, pelo autor, do artigo de Puma et al. ${ }^{11}$.

\section{Descrição do caso clínico}

Dados sociodemográficos: Luís (nome fictício) é um engenheiro de 59 anos, natural e residente em Vila do Conde, Portugal. Insere-se numa família nuclear (fase VII do ciclo de Duvall, Graffar classe II). Tem um filho, Abel (nome fictício), um médico de família de 30 anos (Ver genograma familiar na Figura 1).

História médica pregressa: 1. Rinossinusite crônica; 2. Obesidade grau 1; 3. Hiperplasia Benigna da Próstata; 4. Hábitos tabágicos passados: 27 maços/ano.

Outubro/2010: Luís sempre foi utilizador esporádico dos serviços de saúde. Fazia parte da sua personalidade pré-mórbida uma atitude workaholic.

Em outubro, vai à primeira consulta com seu Médico de Família (MF). Refere sentir-se bem. Bebe $20 \mathrm{~g}$ de álcool por dia e não pratica atividade física.

Ao exame objetivo, apresenta um IMC $=32 \mathrm{~kg} / \mathrm{m}^{2}$ (peso $=96 \mathrm{~kg}$, altura $=1,73 \mathrm{~m})$.

O seu MF solicita exames laboratoriais.

Novembro/2010: Os resultados do estudo analítico documentam uma dislipidemia (colesterol total $=252 \mathrm{mg} / \mathrm{dL}, \mathrm{LDL}=170 \mathrm{mg} / \mathrm{dL}, \mathrm{HDL}=41 \mathrm{mg} / \mathrm{dL}$, triglicerídeos $=205 \mathrm{mg} / \mathrm{dL}$ ). Luís procura conselho junto de seu filho Abel. Abel realça a necessidade de alteração dos estilos de vida, incentivando-o à prática de exercício físico e redução da ingestão de alimentos hipercalóricos. Alerta também para a importância de uma nova consulta com o MF para continuidade de vigilância. 

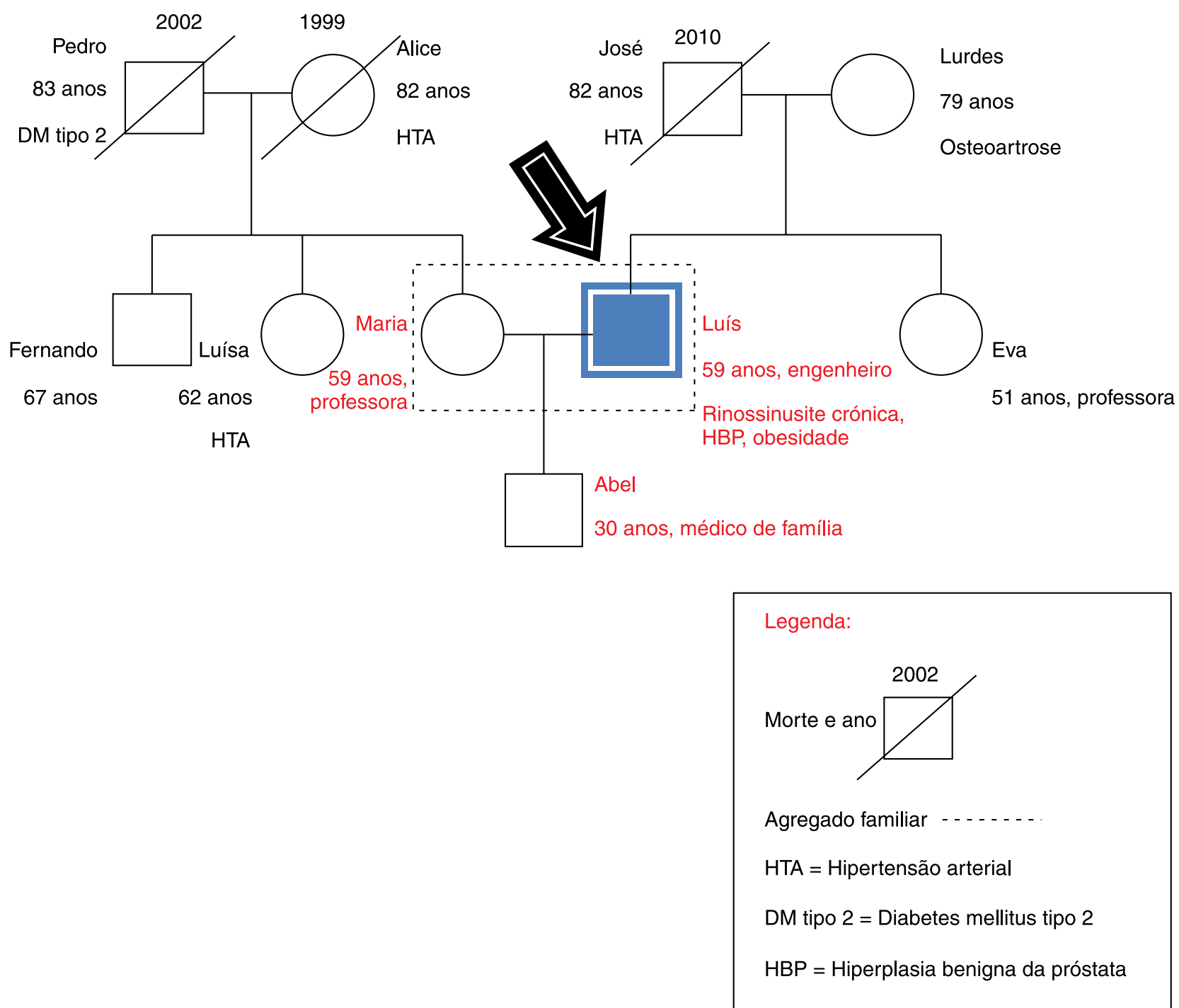

Figura 1. Genograma Familiar de Luís.

Luís náo consulta o MF, mas altera radicalmente o estilo de vida. Inicia caminhadas diárias de 30-60 minutos e aumenta a ingestáo de carnes brancas e peixe (em detrimento de carnes vermelhas), frutas e vegetais.

Março/2011: Luís apresenta uma considerável perda de peso $(10 \mathrm{~kg})$, interpretada como produto da modificação do estilo de vida. Diz sentir-se "fisicamente mais leve e menos cansado para esforços". Tem consulta com o MF, que requisita repetiçáo dos exames laboratoriais.

Abril - Maio/2011: Luís repete as análises, com melhoria global dos parâmetros. Inicia, entretanto, uma tosse náo produtiva e de predomínio diurno. Procura novo aconselhamento com o filho. Nega pirose, pieira ou aperto torácico. Ao exame objetivo, Abel não observa ocorrência posterior ou outra alteração, exceto nova perda de peso (peso $=82 \mathrm{~kg})$. Luís mantém as suas caminhadas, embora referindo um cansaço inespecífico. É feita prova empírica com anti-histamínico e nebulizações de soro hipertônico, com melhoria ligeira dos sintomas.

Junho/2011: Luís refere lombalgias localizadas, moderadas, de ritmo mecânico, com agravamento gradual. Revela rigidez nos primeiros 30 minutos matinais. É medicado pelo filho, com analgésico. Mantém tosse, por vezes semiprodutiva (expectoração serosa e não hemoptoica), e perda ponderal (peso $=81 \mathrm{~kg})$. Reduzira a frequência de caminhada para 3 vezes/semana. Abel recomenda o recurso ao MF, para observaçáo e possível pedido de exames complementares (radiografia pulmonar? prova tuberculínica? espirometria?).

A persistência desta tosse náo produtiva e a perda de peso (agora inexplicada, atendendo ao declínio na prática de exercício físico) criam um abstrato sentimento de alarme em Abel, que teme ser consequência de uma interpretaçáo 
manchada pela afetividade que o liga a Luís. Deseja não se envolver no estudo diagnóstico e explica ao pai a possível interferência da relaçáo filho-pai na desejada objetividade de uma relação médico-paciente. Luís não consulta o $\mathrm{MF}$.

Julho/2011: Por persistência da fadiga associada à tosse e por novo declínio ponderal, Abel procede a um exame objetivo mais extenso no pai, que viria a registrar adenomegalias cervicais posteriores bilaterais e axilares, móveis e de consistência borrachosa.

Abel percebe estar diante de um quadro clínico com elevado grau de suspeição, que pouco poderia ser afetado por uma subjetividade afetiva. São óbvios os sinais de alarme (perda ponderal e adenomegalias) e conclui que terá que apressar o estudo diagnóstico. Relembra as mudanças comportamentais assumidas por Luís ao longo de meses. Todas elas foram iniciadas após o seu aconselhamento médico. Identifica, também, o apelo da mãe Maria para assistência clínica ao pai e o medo de Luís em iniciar qualquer processo de investigação na sua saúde, pontuado por fugas à consulta com seu MF. Abel reconhece, portanto, a solidez e a confiança fornecidas pela afetividade entre pai e filho numa relaçáo que se iniciara de forma casual e imprevista. Ao contrário do que sempre pensara fazer, Abel assumiu-se como médico do seu próprio pai.

Agosto/2011: Em início de Agosto, ambos vão à consulta com seu MF. Abel discute com o colega os sinais de alerta apresentados pelo pai. É pedido TAC pulmonar, cujo resultado revela "adenomegalias mediastínicas, hilares e axilares. Suspeita de doença linfoproliferativa? Neoplasia oculta?”. Concomitantemente, há um agravamento notório das lombalgias, agora de ritmo misto. Abel suspeita de dor oncológica e prescreve analgesia.

Em ambiente familiar, Abel explica ao pai as hipóteses prováveis de diagnóstico e a abordagem provável a seguir. Luís responde: - "Farei o que tu achares que deve fazer". Abel contacta uma colega de Medicina Interna e o estudo é agendado para a semana seguinte.

Luís realiza TAC, que documentaria mútiplas adenopatias cervicais, supraclaviculares, axilares, hilares, mediastínicas e retroperitoneais e alterações vertebrais suspeitas de metastização difusa. Submete-se à biopsia ganglionar, cujo resultado histológico seria "adenocarcinoma (origem gastrointestinal?)".

Abel aborda as expectativas de Luís. Em conversa íntima com o pai, esclarece dúvidas e a necessidade de realizar endoscopia digestiva alta e de esclarecimento de imagens ósseas com cintilograma. Luís não questiona o seu prognóstico e diz: - "Se tu achas que é assim, o caminho é para frente!".

$\mathrm{Na}$ segunda quinzena, as lombalgias agravam-se e confundem-se com um sofrimento psicológico. Luís deseja náo ser pesado, evitando o confronto com a balança. São aumentadas as doses analgésicas. Abel tem conversas com o pai, reforçando a sua presença enquanto médico e filho.

Setembro/2011: O cintilograma revelar-se-ia "compatível com metastização óssea multifocal" e o exame endoscópico documentaria uma lesão do corpo gástrico que, histologicamente, seria um "adenocarcinoma de células não coesas". O doente é orientado para consulta de Oncologia. No dia 5/9/2011, deu entrada no Serviço de Urgência Hospitalar por dispneia, em contexto de tromboembolismo pulmonar maciço, vindo a falecer nesse dia.

\section{Discussão}

A abordagem clínica de familiares constitui um tema antigo, porém não tem sido indagado com a mesma frequência com que surge no cotidiano médico ${ }^{1}$. Perante uma situação que obriga a cuidados prolongados, o MF poderá sentir-se desconfortável, questionando se a sua abordagem será objetiva e se será isenta de emoçóes que possam pavimentar uma intervenção penosa para o próprio médico ${ }^{8}$.

O papel do familiar médico poderá, então, ser uma experiência desafiadora. $\mathrm{O}$ estudo de Chen et al. justifica o caráter difícil dessa experiência ao considerá-la como fruto de uma combinaçáo complexa de quatro expectativas geradoras de conflito interior: duas em nível do domínio pessoal, que incluem a expectativa de ser um membro da família dedicado e aquela de corresponder aos outros familiares; e duas em nível profissional, que integram a expectativa de ser um médico consciencioso e aquela de corresponder aos colegas de profissão ${ }^{8}$.

As respostas a estas expectativas foram colocadas, subliminarmente, ao longo do desenvolvimento deste caso. Abel encontrou uma oportunidade para ser o gestor dos cuidados de saúde centrados no pai, num plano em que já era, simultaneamente, seu filho. Tal como qualquer outro clínico, teria dúvidas relativas à objetividade das suas observaçóes e questionar-se-ia se o seu raciocínio médico não estaria incrustado de emoçôes que comprometessem o seu componente analítico. Tal ficou subentendido na observaçáo de perda ponderal do pai: embora a achando suspeita desde cedo, a procura de objetividade do seu processo cognitivo levou-o a relembrar uma brusca mudança comportamental de estilos de vida como explicaçáo lógica para tal dado.

Entretanto, Abel sentir-se-ia negligente, caso não optasse por uma intervenção ativa (frustrando as expectativas de sua mãe - domínio extrínseco pessoal) ou caso não respondesse às previsíveis solicitaçôes para colaboração com os colegas hospitalares (correspondendo às expectativas destes - domínio extrínseco profissional). 
Neste caso clínico, foi notório que a suspeita de uma condiçâo clínica grave veio consolidar o estabelecimento de uma relação, que, até entáo, carecia de consistência ou de firme existência. Abel terá entendido que a relação familiar iria trazer, neste contexto clínico grave, um grande benefício no estabelecimento de um plano de abordagem sólida, pouco conturbada e menos dolorosa para o pai. Todos os médicos incluídos no estudo de Chen et al. salientaram as deficiências e a complexidade do sistema de saúde como potenciais agravadores do mal-estar sentido pelos seus familiares ${ }^{8}$. Essa complexidade náo seria favorecedora de uma abordagem táo abrangente, centrada na pessoa e respeitadora de uma modelação holística. Abel sentiu, pois, que seria o médico mais especializado naquele indivíduo e, portanto, o mais habilitado para articulaçáo de todos os cuidados.

De fato, perante a evidência de condições clínicas (obesidade, dislipidemia), Luís cumprira todas as recomendações de Abel (como as alteraçôes dos estilos de vida). E perante exames complementares, aguardara sempre a apreciação pelo filho. Tal fez constatar que o médico em quem Luís mais confiara era o seu próprio filho. Não seria, portanto, surpreendente que, perante uma doença oncológica, Luís quisesse ter também esse mesmo médico no seu seguimento.

Neste caso, o impacto da transmissão das más notícias, da abordagem do mau prognóstico e da evoluçáo da dor pôde ser atenuado para o pai por serem realizados pelo filho médico. A dissipação dos receios no doente oncológico torna-se praticamente impossível, mas tornaram-se menos densos com o acompanhamento afetivo e clínico do seu familiar médico. Tal foi particularmente deduzível em expressôes como: - "Se tu achas que é assim, o caminho é para frente!".

Por outro lado, uma das maiores colisóes internas entre o papel de familiar-cuidador e o papel de familiar-médico poderá ocorrer na transmissão de más notícias, como a revelação do prognóstico ${ }^{2,3,8}$. Haverá uma tendência para ocultação de toda a informaçáo pelo lado familiar-cuidador, que deteriore o desempenho enquanto médico correspondente aos direitos do doente ${ }^{3}$. Neste caso, Abel terá ultrapassado essas barreiras, pois, o pai não questionou sobre o prognóstico.

Especialmente em situaçôes clínicas incuráveis e avançadas, é típico um sofrimento psicológico que acompanha a dor orgânica e que dificilmente o clínico consegue atenuar, por muitas competências comunicacionais que possua. Uma terapia familiar é, assim, iniciada por diversas vezes, conferindo aos parentes habilidades afetivas e comunicacionais, que visam a diminuição da angústia da pessoa em condição terminal ${ }^{12}$. Pergunta-se, portanto, se o afeto existente na relação entre dois familiares e, concomitantemente numa relação médicopaciente, não constituirá, por si só, uma parte do tratamento. Esse familiar médico será, provavelmente, o cuidador melhor sucedido no alívio do desconforto daquela pessoa.
Deste caso nasce a dúvida quanto a existência de um código consensual de conduta médica para abordagem de um familiar doente. Questiona-se se tal conduta não deverá, antes, resultar de uma avaliação interpares (familiar-médico e familiar-pessoa) do impacto que tal abordagem terá para a pessoa e para o clínico. Será certo que as recomendaçóes surgem com uma finalidade orientadora perante situaçóes que levantem questóes éticas, emocionais e de competência. Porém, perante um número tão variado de situaçóes clínicas, de contextos sociais e de traços de personalidade envolvidos, tornar-se-á extremamente complexo constituir pareceres, mesmo que meramente orientadores.

\section{Referências}

1. Puma JL, Stocking CB, Voie DL, Darling CA. When physicians treat members of their own families. N Engl J Med. 1991; 1290-94. PMid:1922224. http://dx.doi.org/10.1056/NEJM199110313251806

2. Eastwood GL. When relatives and friends ask physicians for medical advice: ethical, legal and practical considerations. J Gen Intern Med. 2009; 24(12): 1333-5. PMid:19784705 PMCid:2787942. http:// dx.doi.org/10.1007/s11606-009-1127-1

3. Carroll RJ, Tulsky J, Schuchman M, Snyder L. Should doctors treat their relatives? Ethics case study \#21. ACP-ASIM Observer. 1999 [acesso em 2011 nov. 30]. Disponível em: http://www.acpinternist. org/archives/1999/01/relative.htm

4. Hill H, Hill M. When your mother wants a script: the ethics of treating family members. J Am Acad Phys Assistants. 2011; 24(2): 59-60.

5. Snyder L, Leffler C. Ethics and Human Rights Committee, American College of Physicians. Ethics Manuel: fifth edition. Ann Intern Med. 2005; 142(7): 560-82.

6. American Medical Association - AMA. Council on Ethical and Judicial Affairs. Code of Medical Ethics. Opinion 8.19. American Medical Association Press; 2010. [acesso em 2011 nov. 30]. Disponível em: http://www.ama-assn.org/ama/pub/physician-resources/medicalethics/code-medical-ethics/opinion819.page?

7. Conselho Regional de Medicina do Estado do Paraná - CRMPR, Conselho Federal de Medicina - CFM. Resolução CFM n 1931/2009, de 24 de setembro de 2009. Novo código de ética médica. Diário Oficial da República Federativa do Brasil, Brasília, DF, Poder Executivo, set. 2009. Seção 1, p. 90-2.

8. Chen FM, Feudtner C, Rhodes LA, Green LA. Role conflicts of physicians and their family members: rules but no rulebook. West J Med. 2011. 175: 236-9. http://dx.doi.org/10.1136/ewjm.175.4.236

9. Krall EJ. Doctors who doctor self, family and colleagues. Wisc Med J. 2008; 107(6): 279-84.

10. Latessa R, Ray L. Should you treat yourself, family and friends?. Fam Pract Manage. 2005; 41-44. PMid:15813304.

11. Puma JL, Priest ER. Is there a doctor in the house? An analysis of the practice of physicians'treating their own families. JAMA. 1992; 267: 1810-2. http://dx.doi.org/10.1001/ jama.1992.03480130126037

12. Ngo-Metzger Q, August KJ, Srinivasan M, Liao S, Meyskens FL. End-of-life care: guidelines for patient-centered communication. Am Fam Physician. 2008; 77(2): 167-74. PMid:18246886. 